\title{
EDITORIAL
}

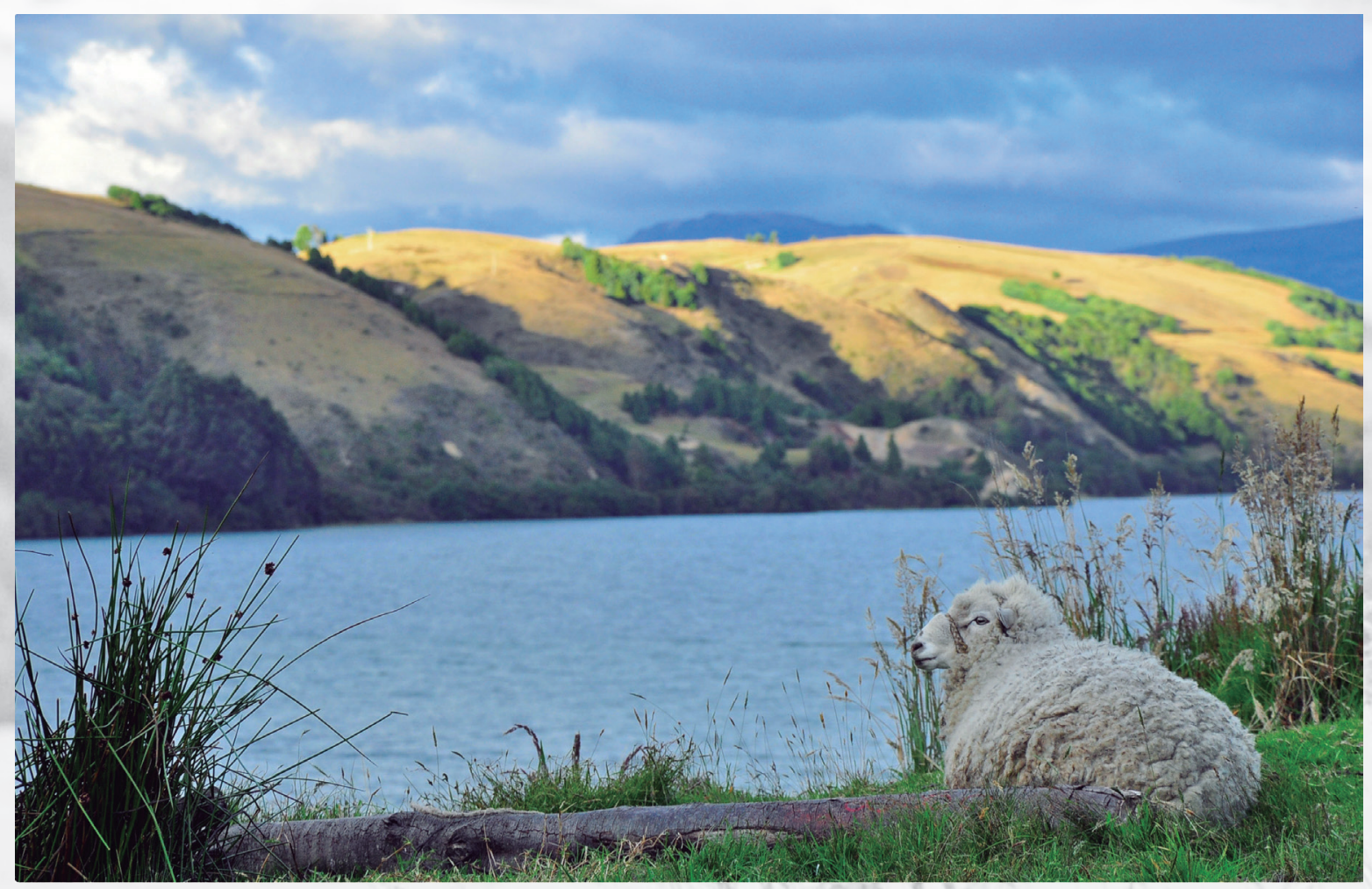

Serie Colombia Territorios Diversos - Beatriz Núñez Arce

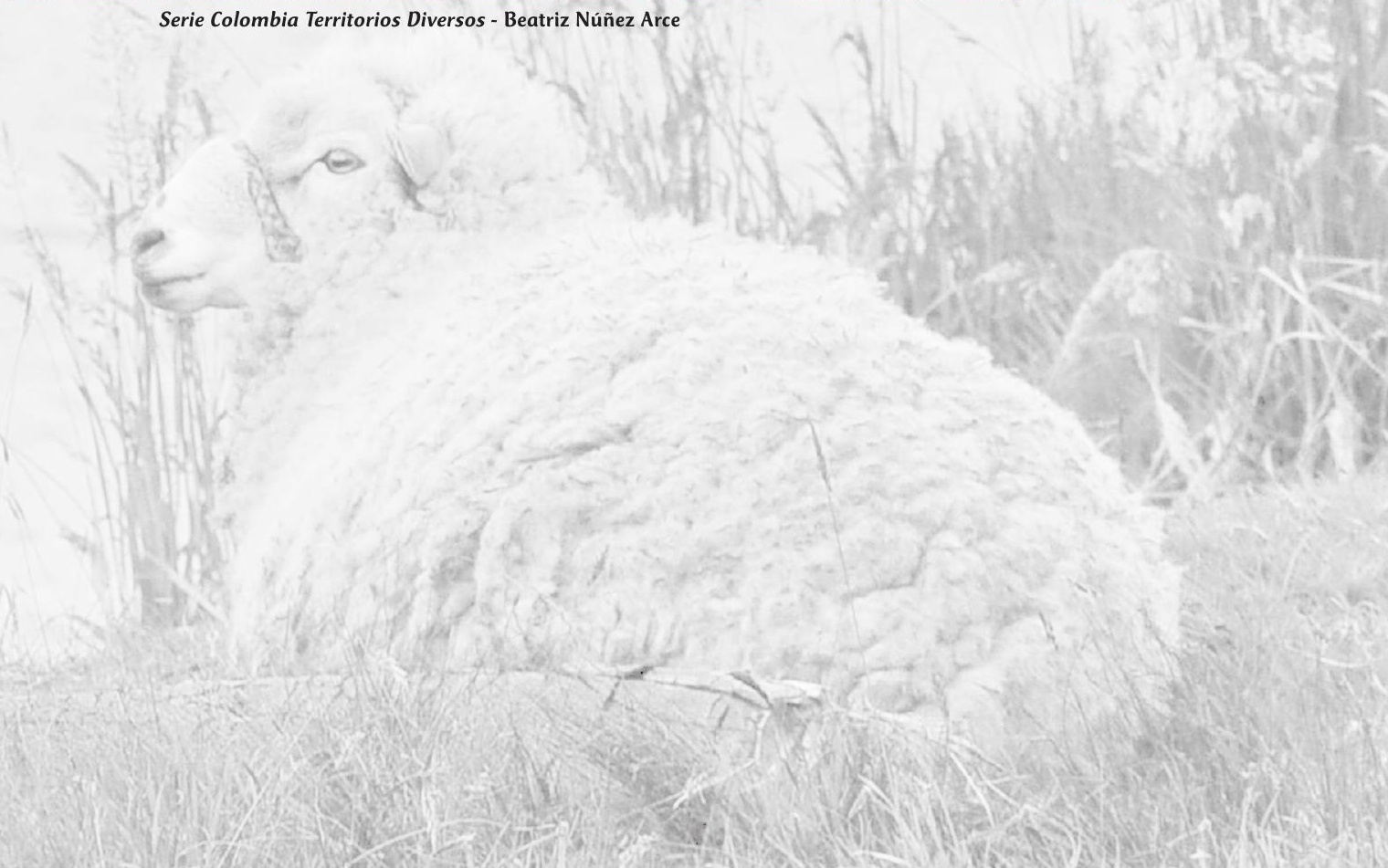





\section{Veinte ediciones de la revista POLISEMIA: aprendiendo de la Noviolencia}

Twenty magazine Polisemia's editions: learning about nonviolence

$\mathrm{P}$ resentamos a nuestros lectores la edición N. 20 de la revista Polisemia. En el mes de Julio del año 2005 apareció su primera edición, en ese entonces bajo la responsabilidad de la Facultad de Ciencias Humanas y Sociales de UNIMINUTO. Han transcurrido 10 años de la vida de esta publicación académica que ha mantenido una frecuencia semestral; y cuya dirección fue asumida desde su primer número por el Centro de Estudios e Investigaciones Humanas y Sociales (CEIHS), más tarde integrado al Centro de Pensamiento de la Universidad.

Son muchos los cambios que han sucedido en esta década convulsionada tanto en el mundo como en el escenario colombiano. Por supuesto, todo ello se ha reflejado en transformaciones enormes en la cobertura y estructura de nuestra Universidad, en la consolidación de procesos de investigación de mayor profundidad y pertinencia, y en la amplitud de miras de Polisemia.

En sus páginas han tenido presencia los escritos de cerca de 100 autores y autoras que han aportado al conocimiento desde distintas posiciones filosóficas y políticas, presentando resultados de sus investigaciones y reflexiones, que han demostrado la posibilidad de establecer un diálogo fecundo en medio del pluralismo epistemológico y metodológico que inspira el quehacer universitario en UNIMINUTO.

Hoy contamos con un Comité Editorial y un Comité Científico, de los que forman parte pensadores sociales de notable producción académica, tanto de nuestra Universidad como de distintas instituciones internacionales que conforman algunas de las redes de producción de conocimiento que respaldan a Polisemia. Las temáticas siguen abiertas al arcoíris de los problemas que emergen de la sociedad para interrogar a la academia, pero se han decantado de forma gradual hacia tres grandes líneas de trabajo paz, desarrollo y ciudadanía-, atravesadas por las concepciones y las prácticas de la Noviolencia.

Justamente son los dolores de la guerra, así como las expectativas de una transición hacia formas de convivencia pacífica que pasen por una salida negociada del largo conflicto armado colombiano, lo que ha hecho amplificar las investigaciones sobre la refundación del tejido ciudadano, potenciado por el surgimiento de nuevas ciudadanías. Y, entrelazadas con ellas, se aprecia la alborada de territorialidades

1 Doctor en Paz Conflictos y Democracia, Universidad de Granada. Director de la revista Polisemia de la Corporación Universitaria Minuto de Dios UNIMINUTO 
emergentes que van preñando de nuevas formas de relacionamiento la geografía humana colombiana.

Lo anterior ha implicado el análisis múltiple de los territorios existenciales desde donde se resiste a los modelos de desarrollo imperantes; y el énfasis en seguir las huellas de los lugares para la vida, en los cuales se despliega una nueva ecología de las relaciones humanas y de las relaciones con la naturaleza, que hagan posible la reinscripción de unos seres humanos no escindidos de la biosfera, que la respeten como su hábitat secular y la conciban como un organismo vivo, no como una mera fuente de recursos para la producción y la riqueza. Indagar por alternativas al desarrollo es, entonces, un imperativo de una paz profunda con justicia social y reparación de los millones de víctimas que ha dejado la guerra colombiana.

La noviolencia, transversal a estos procesos de un dinamismo extraordinario, se ha ido erigiendo como un valioso enfoque transformador. Se enfoca en auspiciar los trayectos de cambio cultural y los procesos de subjetivación con los que se constituyen comunidades creativas que diseñan sus autonomías y prohíjan los acontecimientos de mundos nuevos, que serán el soporte de formas otras de convivir.

La paz se basa en el reconocimiento de la diferencia y de los conflictos, entendidos como una potente expresión de la vitalidad social, propugnando por su transformación limpia de violencia. Se trata de comprender la unidad como una permanente y móvil conectividad de lo diverso. De allí surge lo que es común a todos y a todas. Esa es la fábrica de los bienes comunes, aquellos como la biodiversidad, el agua, el aire, la tierra, la paz, la felicidad y una comprensión reticular, autoorganizada y no jerarquizada de la democracia, expresión de la sociedad en movimiento.

Tal es la deriva para profundizar en la crítica de los modelos de desarrollo dominantes. Como hemos señalado en otros editoriales (cfr. Polisemia, N. ${ }^{\circ}$ 15) el mundo se ha empobrecido a causa de la expansión totalizante del neoliberalismo que pretende convertirlo todo en mercancía, incluso al ser humano mismo, a la biosfera íntegra. Estamos avocados a soñar en las libertades abstractas conforme al discurso occidental; lo que no nos está permitido es desear estar por fuera del mercado que se ha ido configurando, al lado de la guerra perpetua, en la institución que constituye la pertenencia a la sociedad, e incluso, el borroso concepto de ciudadanía.

La economía única del mercado ha intentado homogenizar la multiplicidad de formas de producción y distribución procurando sujetar, hacer desaparecer o invisibilizar las oikonomías ${ }^{2}$, fruto de los encuentros cotidianos para producir valores de uso o para el intercambio horizontal de bienes, cargados de valores simbólicos que permiten renovar los vínculos solidarios y comunitarios. Ahora el signo que todo lo enuncia es la ganancia y desde allí se pretende que todo se simplifique, incluso los valores más caros, a los grupos humanos y las sociedades o la misma ecosfera, en la precaria condición de mercancías dispuestas para la obtención de rentas.

Por eso, las propuestas de alternativas al desarrollo han planteado la perspectiva de "(...) una verdadera multiplicidad de configuraciones político-culturales, diseños socio-ambientales y modelos económicos". Es desde la diferencia y el poder de lo múltiple que se pueden repensar caminos para superar la crisis sistémica del capital, que ha demostrado no poder garantizar las posibilidades de la vida social y natural.

Parte de esa crisis es la extensión del monstruo de la guerra a todos los confines planetarios. Los horrendos atentados contra los civiles en París, ocurridos en este mes de noviembre, muestran las heridas abiertas de los conflictos coloniales producidos por las acciones bélicas de saqueo de las potencias occidentales. Es la degradación de la vida humana. Los fanáticos terroristas que esgrimen el Islam como justificación, intentan igualar

2 Oikonomía: del griego Oikos, hogar, casa. Comunidad humana básica. Oikonomía sería la forma de administrar el hogar, la hacienda o esa comunidad básica en materia económica. 
en capacidad de infligir dolor indiscriminado a quienes bombardean sus territorios. Nada puede legitimar una guerra atroz. La muerte y el odio solo reproducen los poderes dominantes.

Como nunca, hoy se requieren políticas fundadas en la hermandad, la justicia y el amor. La Noviolencia hace un importante aporte en esta dirección. Asimismo, compartimos la propuesta fotográfica de Beatriz Núñez Arce Serie Colombia Territorios diversos, en la que se muestra en palabras de la artista:

[...] una reflexión sobre Colombia como territorio diverso. El paisaje mezclado con lo cotidiano, por- que en tiempos de diálogos y futuro posconflicto, no se puede pensar en un territorio magnificado por el turismo, postales o documentales, o destruido por los medios sensacionalistas o la oposición guerrerista. Es utilizar el contraste entre la tierra de rincones llenos de maravillas que hacen parte de todos, y la vida cotidiana que sigue reclamando ese territorio olvidado y que no es exclusivo de los que tienen el poder, sino de todo aquel que lucha para visibilizarse dentro de este (Núñez, 2015).

De este modo, en esta edición N. ${ }^{\circ} 20$ de Polisemia convocamos a ahondar en su filosofía y en sus aprendizajes prácticos, que contribuyen a la emergencia de mundos nuevos. 